\title{
Use of the nested polymerase chain reaction for detection of Toxoplasma gondii in slaughterhouse workers in Thika District, Kenya
}

\author{
S K Thiong',,${ }^{1} \mathrm{BSc} ; \mathbf{J}$ M Ichagichu, ${ }^{2} \mathrm{MSc} ; \mathbf{M}$ Ngotho, ${ }^{2} \mathrm{PhD} ; \mathbf{G} \mathrm{O}$ Aboge,${ }^{3} \mathrm{PhD} ; \mathbf{J}$ M Kagira,${ }^{4} \mathrm{PhD} ; \mathbf{S} \mathbf{M}$ Karanja, ${ }^{4} \mathrm{PhD}$; \\ N N Maina, ${ }^{1,4} \mathrm{PhD}$ \\ ${ }^{1}$ Department of Molecular Biology and Biotechnology, Pan African University Institute for Basic Science Technology and Innovation, \\ Nairobi, Kenya \\ ${ }^{2}$ Animal Sciences Department, Institute of Primate Research, Karen, Nairobi, Kenya \\ ${ }^{3}$ Department of Public Health Pharmacology and Toxicology, Faculty of Veterinary Medicine, University of Nairobi, Kenya \\ ${ }^{4}$ Jomo Kenyatta University of Agriculture and Technology, Nairobi, Kenya
}

Corresponding author: N N Maina (nmaina@hotmail.com,nmaina@jkuat.ac.ke)

\begin{abstract}
Background. The widely used methods of diagnosis of Toxoplasma gondii are serological. Current reports indicate a high seroprevalence of $T$. gondii in humans in Kenya. There is a need for more sensitive diagnostic tests, especially when the specific antibody titres are below detectable threshold levels. Use of the polymerase chain reaction (PCR) targeting the repetitive 529 base pair loci has been reported to be sensitive and specific. Objective. To detect $T$. gondii in a high-risk group of public health workers in Thika District, Kenya.

Methods. In total, 87 human blood samples were collected from male slaughterhouse workers between 1 March 2013 and 25 June 2013 . The DNA extracted was amplified by the nested PCR.

Results. T. gondii was detected in 39.1\% (34/87) of the workers. In the cow-sheep-goat slaughterhouses the prevalence ranged between $20 \%$ and $60 \%$, while all the chicken slaughterhouse workers $(6 / 6,100 \%)$ tested positive. The difference in $T$. gondii positivity between the workers in the chicken slaughterhouse and those in the cattle-sheep-goat slaughterhouses was statistically significant $(p=0.003)$.

Conclusion. This study shows the presence of T. gondii in an asymptomatic high-risk group in Thika District, indicating the need for enhancement of public health awareness.
\end{abstract}

S Afr Med J 2016;106(4):417-419. DOI:10.7196/SAMJ.2016.v106i4.8777

Toxoplasma gondii is an intracellular protozoan parasite that infects a wide range of warm-blooded animals. The parasite causes toxoplasmosis in humans, which manifests as mild nonspecific infection or may be asymptomatic in immunocompetent hosts. ${ }^{[1]}$ In immunocompromised humans T. gondii infection may lead to cerebral toxoplasmosis. ${ }^{[2]}$ In addition, congenitally acquired toxoplasmosis can have severe and life-threatening consequences such as abortion, stillbirth, abnormal enlargement or reduction in child head size, mental retardation, vision loss and seizures. ${ }^{[1,3]}$

The keeping of livestock (pigs, cows, poultry and goats) in highly populated urban areas, as occurs in Thika District, increases the risk for transmission of zoonoses such as toxoplasmosis. ${ }^{[4,5]}$ A recent study of farmers in Thika District identified potential risk factors for transmission of toxoplasmosis, including the keeping of cats allowed to range freely outside the home (the cat being the definitive host of T. gondii), improper handling and disposal of cat faeces (by the few owners who provided cat litter boxes) and livestock manure, and consumption of untreated water. ${ }^{[6]}$

The current diagnostic methods are mainly serological. Studies of the prevalence of toxoplasmosis in Kenya are few. One report indicates prevalence of between $35 \%$ and $60 \%$ in preschool children. ${ }^{[7]}$ The use of nested polymerase chain reaction(nPCR) has been shown to be more sensitive and specific for detection of T. gondii than the serological tests. ${ }^{[8]}$ The targeted genes include $18 \mathrm{~S}$ ribosomal DNA, the B1 multicopy element, $S A G 1, S A G 2$ and the 529 base pair (bp) multicopy element. Previous studies have shown that the 200 - 300-fold 529 bp repeat element is a reliable target. ${ }^{[9]}$ Using this target, we determined the presence of T. gondii in slaughterhouse workers in Thika District.

\section{Methods}

Study group

The study group comprised licensed abattoir workers in Thika District, which covers $1960.2 \mathrm{~km}^{2}$ and lies between $3^{\circ} 53^{\prime}$ and $1^{\circ} 45^{\prime} \mathrm{S}$ and $36^{\circ} 35^{\prime}$ and $37^{\circ} 25^{\prime} \mathrm{E}$.

\section{Sample collection and processing}

Using a standard venepuncture technique, $4 \mathrm{~mL}$ human blood samples were collected from consenting workers. The blood was transferred to labelled sterile tubes, which were immediately stored in an upright position in a refrigeration coolbox. The blood samples were transported to the laboratory within 5 hours of collection, and stored upright at $+4^{\circ} \mathrm{C}$ overnight before separation of serum. Serum was separated from the blood samples by pipetting and samples were stored in aliquots of $200 \mu \mathrm{L}$ at $-20^{\circ} \mathrm{C}$ until analysed.

\section{Ethical approval}

Permission to undertake the study was obtained from the institutional ethical review committee of Kenya Medical Research Institute. The workers were informed about the study, and those who gave written consent were included.

\section{DNA isolation}

DNA was extracted from the serum samples using Quick-gDNA ${ }^{\mathrm{TM}}$ MiniPrep kit (Zymo Research, USA) according to the manufacturer's instructions. The extracted DNA was stored at $-20^{\circ} \mathrm{C}$ in DNase-free Eppendorf tubes. 


\section{Positive control}

Reference T. gondii (RH) DNA was kindly donated by the Friedrich-Loeffler-Institut Bundesforschungsinstitut für Tiergesundheit in Germany, through the assistance of Dr Gereon Schares.

\section{PCR technique}

Nested PCR targeting the 529 bp multicopy gene element (GenBank Accession No. AF146527) was performed as previously described. ${ }^{[10]}$ The reaction mixture for primary amplification was optimised in $10 \mu \mathrm{L}$ reaction volume. The components of the PCR reaction mix included $2 \mu \mathrm{L}$ of $10 \times$ Dream Taq buffer (Thermo Scientific, USA), $0.15 \mu \mathrm{L}$ of $5 \mu \mathrm{M}$ of each of the primer pair 5'TGACTCGGGCCCAGCTGCGT3' and 5'CTCCTCCCTTCGTCCAAGCCTCC3', $0.5 \mu$ of Dream Taq polymerase (Thermo Scientific, USA), $0.5 \mu \mathrm{L}$ of DNA template, and $0.2 \mu \mathrm{L}$ of $10 \mathrm{mM}$ dNTP mix; the reaction volume was then topped with double-distilled water. The PCR reaction was run for 30 cycles of denaturation temperature at $94^{\circ} \mathrm{C}$ for 1 minute, annealing at $58^{\circ} \mathrm{C}$ followed by an extension at $72^{\circ} \mathrm{C}$.

In the secondary amplification, the primary PCR amplification product was diluted 1:99 using double-distilled water. From the dilution product, $0.5 \mu \mathrm{L}$ was used as template. The reaction mixture was composed of $2.1 \mu \mathrm{L}$ of $10 \times$ Dream Taq buffer (Thermo Scientific, USA) and $0.5 \mu \mathrm{L}$ of $5 \mu \mathrm{M}$ of each primer pair 5'AGGGACAGAAGTCGAAGGGG3'and 5'GCAGCCAAGCCGGAAACATC3'. A volume of $1 \mu \mathrm{L}$ of Dream Taq polymerase (Thermo Scientific, USA) was added and the reaction volume topped up to $10 \mu \mathrm{L}$ with double-distilled water.

PCR was then run for 35 cycles of denaturation temperature at $94^{\circ} \mathrm{C}$ for 1 minute, annealing at $52^{\circ} \mathrm{C}$, followed by an extension at $72^{\circ} \mathrm{C}$. The reference $T$. gondii (RH) DNA was used as positive control, while PCR water was used as the negative control. The two controls were included in every amplification step.

The product generated in the second amplification was run in $1.5 \%$ agarose gel prestained with $3 \mu \mathrm{L}$ of ethidium bromide $(1 \mu \mathrm{g} / \mathrm{mL})$.

\section{Statistical analysis}

Fisher's exact test was used to determine significance of differences in $T$. gondii positivity between the chicken slaughterhouse workers and the cattle-sheep-goat slaughterhouse workers. Statistical analysis was performed with Epi-Info software (version 6, Centers for Disease Control,
USA); $p$-values $<0.05$ were considered to be significant.

\section{Results}

The primary PCR product was characterised by multiple bands of various sizes, sharp and faint bands equivalent to 400 bp being observed in some samples and the positive control, as shown in Fig. 1. The secondary amplification product clearly showed the predicted amplicon size of 164 bp as shown in Fig. 2.

In six of the eight slaughterhouses, workers tested positive for toxoplasma DNA (Table 1). None of the workers in the Mundoro and Gachika slaughter slabs tested positive. The chicken slaughterhouse recorded the highest prevalence, followed by the Thika slaughter slab with $60.0 \%$. Overall, 39.1\% (34/87) of the workers tested positive for $T$. gondii.

The prevalence of $T$. gondii among the workers $(n=6)$ in the chicken slaughterhouse was significantly higher than among workers $(n=81)$ in the seven cattle-sheep-goat slaughterhouses ( $100 \%$ v. $34.6 \%$; $p=0.003)$, when these were compared as two different study sites based on type of livestock slaughtered.

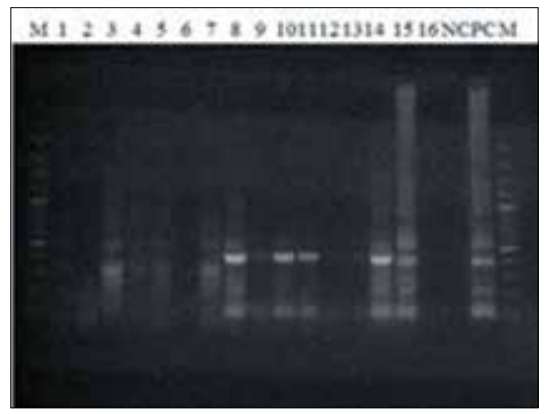

Fig. 1. Gel photograph of primary PCR product showing bands of various sizes. The human serum samples are shown by lanes $1-16 . N C$, $P C$ and $M$ denote the negative control, positive control and $100 \mathrm{bp}$ ladders, respectively.

\section{Discussion}

This is the first study on the prevalence of T. gondii in a suburban setting (Thika District, Kenya). The study demonstrated that up to $39.1 \%$ of the slaughterhouse workers were infected with T. gondii, as detected using nPCR. Higher seroprevalences of $T$. gondii have been reported in schoolchildren (60\%) and human blood donors (54\%) in Nairobi, Kenya. ${ }^{[7,11]}$ Earlier studies in Tanzania have reported T. gondii infection among abattoir workers and livestock keepers, ${ }^{[12]}$ and may indicate an occupational risk of T. gondii transmission. In Poland, high T. gondii seroprevalences have been recorded in abattoir workers from meat factories in Lublin. ${ }^{[13]}$ Among the three slaughter divisions, the Cured Meat Division recorded the highest rate (76.2\%), followed by the Meat Production Division (66.6\%) and the Slaughter Division (46.1\%), compared with a reference blood donor group with a seroprevalence of $55.7 \% .{ }^{[13]}$ In the current study, the highest prevalences of T. gondii infection were noted in the Ruiru and Thika abattoirs. These are in urban areas with mixed economic activities including keeping of livestock such as cattle, sheep, goats and chickens. The two sites are also characterised by clustered dwellings because of their high population density, compared with Mundoro, Gachika and Gathage, which

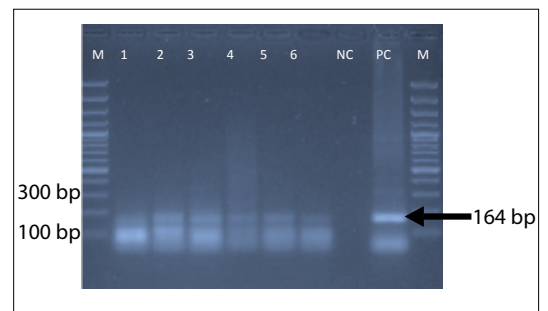

Fig. 2. Gel photograph for secondary PCR amplification product. The human serum samples are represented by lanes $1-6 . N C, P C$ and $M$ denote the negative control, positive control and $100 \mathrm{bp}$ ladders, respectively.
Table 1. Male workers who tested positive for $T$. gondii DNA using nPCR

\begin{tabular}{lll}
\hline Study site & $\begin{array}{l}\text { Type of livestock } \\
\text { slaughtered }\end{array}$ & $\begin{array}{l}\text { Workers testing } \\
\text { positive } \boldsymbol{n} / \boldsymbol{N}(\%)\end{array}$ \\
\hline Chicken slaughterhouse & Chicken & $6 / 6(100.0)$ \\
Thika slaughter slab & Cattle, sheep, goats & $6 / 10(60.0)$ \\
Ruiru slaughterhouse & Cattle, sheep, goats & $10 / 22(45.5)$ \\
Juja slaughter slab & Cattle, sheep, goats & $6 / 15(40.0)$ \\
Municipal slaughterhouse & Cattle, sheep, goats & $5 / 14(35.7)$ \\
Gathage slaughter slab & Cattle, sheep, goats & $1 / 5(20.0)$ \\
Mundoro slaughter slab & Cattle, sheep, goats & $0 / 10(0.0)$ \\
Gachika slaughter slab & Cattle, sheep, goats & $0 / 5(0.0)$
\end{tabular}


are rural sites. Risk factors for T. gondii transmission in the urban setting may therefore be more concentrated than in the rural areas as a result of environmental contamination.

The significantly higher infection level in chicken slaughterhouse workers may indicate higher exposure to T. gondii. Free-range chickens feed off the ground and are a good indicator of the oocysts in soil. Chickens are in fact increasingly being identified as important sources of $T$. gondii in Kenya ${ }^{[14]}$ and in other developing countries. ${ }^{[15]} \mathrm{New}$ toxoplasma infections in slaughterhouse workers may be minimised by thorough washing of hands and working tools after handling animal carcasses, especially chickens. Meat and meat products should be sufficiently cooked or processed to destroy the infective stages of $T$. gondii.

The slaughterhouse workers were asymptomatic. T. gondii infection in immunocompetent humans is usually asymptomatic and therefore remains unrecorded. ${ }^{[16]}$ One report has shown that nearly $25 \%$ of Ugandan HIV patients with neurological complications tested positive for toxoplasmosis as a result of parasite reactivation. ${ }^{[17]}$ The prevalence of HIV among adults aged 15 - 49 years in Thika District is around 6\%, ranking 11 th of 47 Kenyan districts. ${ }^{[18]}$ As a result of the high HIV prevalence in the study area, there is a higher possibility of reactivation of the parasite, leading to severe outcomes. This study and previous ones ${ }^{[7,11,19]}$ indicate the need for strategies to control toxoplasmosis in Kenya.

In this study, T. gondii DNA was detected by nPCR. Serological methods have limitations such as long and laborious test procedures and low sensitivity due to low antibody levels. ${ }^{[20]}$ Detection of T. gondii DNA in blood samples by nPCR, based on the multilocus 529 bp element, was found to be more sensitive than targeting $B 1$ repeat loci, and moreover was highly specific. ${ }^{[10]}$ This finding showed that blood samples can reliably be used as alternative samples for toxoplasmosis studies by PCR, as suggested previously in ocular toxoplasmosis studies. ${ }^{[21]}$ However, the sensitivity of PCR may be limited by the random distribution of the parasite and varying parasite densities in affected tissue. ${ }^{[22]}$ Currently there is no consensus on test protocols and sensitivity for clinical diagnosis of toxoplasmosis by PCR using various samples, ${ }^{[23]}$ and it has therefore been suggested that there is a need to develop more acceptable reference guides for the performance and result validation of PCR techniques. ${ }^{[24]}$ The cost of PCR is high and its application under field conditions is limited by the need for a thermocycler. Alternative amplification of DNA by loop-mediated isothermal amplification, using the 529 element, has been determined ${ }^{[10,25]}$ and should be developed further for application in point-of-care diagnosis.

\section{Conclusion}

In Thika District, up to $39.1 \%$ of slaughterhouse workers are infected with T. gondii, with the highest infection rate being recorded in the chicken slaughterhouse workers. This study implies a need for public health intervention to limit environmental contamination.
Acknowledgement. This research was supported by the African Union and the government of the Republic of Kenya. We acknowledge Gereon Schares at the Friedrich-Loeffler-Institut Bundesforschungsinstitut für Tiergesundheit in Germany for providing the toxoplasma RH-positive control. We also thank Dawn Maranga and Samson Mutura at the Institute of Primate Research for technical assistance.

\section{References}

1. Montoya JG. Laboratory diagnosis of Toxoplasma gondii infection and toxoplasmosis. J Infect Dis 2002;185(Suppl 1):S73-S82. DOI:10.1086/338827

2. Naqi R, Azeemuddin M, Ahsan H. Cerebral toxoplasmosis in a patient with acquired immunodeficiency syndrome. J Pak Med Assoc 2010;60(4):316-318

syndrome. J Pak Med Assoc 2010;60(4):316-318
3. Ghazaei C. Serological survey of antibodies to Toxoplasma gondii. Afr J Health Sci 2006;13(1-2):131134. DOI:10.4314/ajhs.v12i3.30808

134. DOI:10.4314/ajhs.v12i3.30808
4. Kagira JM, Kanyari PWN, Munyua WK, Waruiru RM. The control of parasitic nematodes in commercial piggeries in Kenya as reflected by a questionnaire survey on management practices. Trop Anim Health Prod 2003;35(1):79-84. DOI:10.1023/A:1022031806486

5. Huong LTT, Dubey JP. Seroprevalence of Toxoplasma gondii in pigs from Vietnam. J Parasitol 2007; 93(4):951-952. DOI:10.1645/GE-1163R.

6. Ogendi E, Maina N, Kagira J, Ngotho M, Mbugua G, Karanja S. Questionnaire survey on the occurrence of risk factors for Toxoplasma gondii infection amongst farmers in Thika District, Kenya. J S Afr Vet Assoc 2013;84(1). DOI:10.4102/jsava.v84i1.191

7. Bowry TR, Camargo ME, Kinyanjui M. Sero-epidemiology of Toxoplasma gondii infection in young children in Nairobi, Kenya. Trans R Soc Trop Med Hyg 1986;80(3):439-441. DOI:10.1016/00359203(86)90336-6

8. El-Madawy SR, Metawea FY. Serological assays and PCR for detection of Toxoplasma gondii infection in an ostrich farm at Ismailia Province, Egypt. J Agric Vet Sci 2013;2(3):56-60. DOI:10.9790/2380-0235660 Reischl U, Bretagne S, Kruger D, Ernault P, Costa JM. Comparison of two DNA targets for the diagnosis Reischl U, Bretagne S, Kruger D, Ernault P, Costa JM. Comparison of two DNA targets for the diagnosis
of toxoplasmosis by real-time PCR using fluorescence resonance energy transfer hybridization probes. of toxoplasmosis by real-time PCR using fluorescence

10. Kong QM, Lu SH, Tong QB, et al. Loop-mediated isothermal amplification (LAMP): Early detection of Toxoplasma gondii infection in mice. Parasit Vectors 2012;5:2. DOI:10.1186/1756-3305-5-2

11. Griffin L, Williams KAB. Serological and parasitological survey of blood donors in Kenya for toxoplasmosis. Trans R Soc Trop Med Hyg 1983;77(6):763-766. DOI:10.1016/0035-9203(83)90283-3]

12. Swai ES, Schoonman L. Seroprevalence of Toxoplasma gondii infection amongst residents of Tanga District in north-east Tanzania. Tanzan J Health Res 2009;11 (4):205-209. DOI:10.4314/thrb.v1 1i4.50178 3. Sroka J, Zwoliński J, Dutkiewicz J. The prevalence of anti-Toxoplasma gondii antibodies among abattoir workers in Lublin. Wiad Parazytol 2003;49(1):47-55.

14. Dubey JP, Hill DE, Jones JL, et al. Prevalence of viable Toxoplasma gondii in beef, chicken and pork from retail meat stores in the United States: Risk assessment to consumers. J Parasitol 2005b;91(5):1082-1093. DOI:10.1645/GE-683.1

15. Kijlstra A, Jongert E. Control of risk of human toxoplasmosis transmitted by meat. Int J Parasitol 2008;38(12):1359-1370. DOI:10.1016/j.jpara.2008.06.002

16. Surveillance and monitoring of Toxoplasma in humans, foods and animals: Scientific Opinion of the Surveillance and monitoring of Toxoplasma in humans, foods and animals: Scientific Op
Panel on Biological Hazards. EFSA Journal 2007;583:14-64. DOI:10.2903/j.efsa.2007.583

17. Lindström I, Kaddu-Mulindwa DH, Kironde F, Lindh J. Prevalence of latent and reactivated Toxoplasma gondii parasites in HIV-patients from Uganda. Acta Trop 2006;100 (3):218-222. DOI:10.1016/j. actatropica.2006.11.002

18. National AIDS Control Council (NACC)/National AIDS and STI Control Programme (NASCOP). National HIV Prevalence in Kenya: Kenya AIDS Indicator Survey, 2007. Nairobi: NASCOP, 2007.

19. Lodenyo H, Sitati SM, Rogena E. Reactivated toxoplasmosis presenting with non-tender hepatomegaly in a patient with HIV infection. Afr J Health Sci 2007;14(1-2):97-98. DOI:10.4314/ajhs.v14i1.30852

20. Sensini A. Toxoplasma gondii infection in pregnancy: Opportunities and pitfalls of serological diagnosis Clin Microbiol Infect 2006;12(6):504-512. DOI:10.1111/j.1469-0691.2006.01444.x]

21. Khan A, Jordan C, Muccioli C, et al. Genetic divergence of Toxoplasma gondii strains associated with ocular toxoplasmosis, Brazil. Emerg Infect Dis 2006;12(6):942-949. DOI:10.3201/eid1206.060025

22. Hill DE, Chirukandoth S, Dubey JP, Lunney JK, Gamble HR. Comparison of detection methods for Toxoplasma gondii in naturally and experimentally infected swine. Vet Parasitol 2006;141(1-2):9-17. DOI:10.1016/j vetpar.2006.05.008

23. Ivović $\mathrm{V}$, Vujanić $\mathrm{M}$, Živković T, Klun I, Djurković-Djaković O. Molecular detection and genotyping of Toxoplasma gondii from clinical samples. In: Djurković-Djaković O, ed. Toxoplasmosis - Recen Advances. Science, Technology and Medicine open access publisher, 2012: ch. 5. DOI:10.5772/50830

24. Kaiser K, van Loon AM, Pelloux H, et al. Multicenter proficiency study for detection of Toxoplasma gondii in amniotic fluid by nucleic amplification methods. Int J Clin Chem 2007;375(1-2):99-103. DOI:10.1016/j.cca.2006.06.016

25. Zhang H, Thekisoe OM, Aboge GO, et al. Toxoplasma gondii: Sensitive and rapid detection of infection by loop-mediated isothermal amplification (LAMP) method. Exp Parasitol 2009; 122(1):47-50 DOI:10.1016/j.exppara.2009.01.012

Accepted 18 March 2015. 